\title{
FÓRUM
}

Submetido em 29.11.2013. Aprovado em 05.06.2014

Avaliado pelo sistema double blind review. Editores Científicos: Maria Tereza Saraiva de Souza, Orlando Cattini Junior e

José Carlos Barbieri

http://dx.doi.org/10.1590/S0034-759020140505

\section{GREEN SUPPLY CHAIN: PROTAGONISTA OU COADJUVANTE NO BRASIL?}

\author{
Green Supply Chain: a protagonist or a supporting role in Brazil? \\ Green Supply Chain: ¿protagonista o coadyuvante en Brasil?
}

\begin{abstract}
RESUMO
Questões ambientais passaram a ser introduzidas com maior frequência nos negócios empresariais. Quanto à cadeia de suprimentos, Green Supply Chain Management (GSCM) surge como novo enfoque à responsabilidade das empresas com o meio ambiente. Este artigo objetiva analisar a difusão do conceito e das práticas de GSCM no cenário brasileiro. Para tanto, foram realizadas entrevistas com especialistas do tema cadeia de suprimentos na área de Administração no Brasil. Os resultados indicam que as razões para o lento desenvolvimento do conceito podem relacionar-se com características do mercado nacional, foco empresarial em aspectos internos, falta de legislação rígida e baixa pressão dos consumidores. Especialistas percebem, entretanto, boas perspectivas para o futuro das discussões da temática no País, em virtude da Política Nacional dos Resíduos Sólidos, de pressões do mercado internacional e da busca por certificação ambiental. Este estudo procurou fomentar novas discussões sobre GSCM no Brasil.
\end{abstract}

PALAVRAS-CHAVE | Green Supply Chain Management, cadeia de suprimento verde, gestão ambiental na cadeia de suprimentos, sustentabilidade, cenário brasileiro.

\section{ABSTRACT}

Environmental issues began to be introduced more frequently in corporate business. As for the supply chain, Green Supply Chain Management (GSCM) emerges as a new approach to corporate responsibility towards the environment. This article aims to analyze the diffusion of the GSCM concept and practices in the Brazilian scenario. To do that, we conducted interviews with experts on the subject of the supply chain in the area of Management in Brazil. The results show that the reasons for the slow development of the concept may relate to characteristics of the domestic market, corporate focus on internal aspects, lack of strict legislation, and low consumer pressure. Experts notice, however, good prospects for the future of discussions on the subject in the Country, due to the National Solid Waste Policy, pressure from the international market, and the search for environmental certification. This study sought to foster further discussions on GSCM in Brazil.

KEYWORDS I Green Supply Chain Management, green supply chain, environmental management in the supply chain, sustainability, Brazilian scenario.

\author{
ANA PAULA FERREIRA ALVES \\ anapfalves@gmail.com \\ Mestre em Administração de \\ Empresas pelo Programa de Pós- \\ Graduação em Administração da \\ Universidade Federal do Rio Grande \\ do Sul - Porto Alegre - RS, Brasil

\section{LUIS FELIPE MACHADO DO NASCIMENTO \\ nascimentolf@gmail.com Professor do Programa de Pós- Graduação em Administração da Universidade Federal do Rio Grande do Sul - Porto Alegre - RS, Brasil}

\section{RESUMEN}

Las cuestiones ambientales pasaron a ser introducidas con mayor frecuencia en los negocios empresariales. En cuanto a la cadena de suministros, Green Supply Chain Management (GSCM) surge como el nuevo enfoque a la responsabilidad de las empresas con el medio ambiente. Este artículo tiene como objetivo analizar la difusión del concepto y de las prácticas de GSCM en el escenario brasileño. Para esto, se llevaron a cabo entrevistas con especialistas sobre el tema cadena de suministros en el área de Administración en Brasil. Los resultados indican que las razones para el lento desarrollo del concepto pueden relacionarse con características del mercado nacional, objetivos empresariales en aspectos internos, falta de legislación rígida y baja presión de los consumidores. Los especialistas notan, sin embargo, buenas perspectivas para el futuro de las discusiones de la temática en el país, en virtud de la Política Nacional de Residuos Sólidos, de presiones del mercado internacional y de la búsqueda por la certificación ambiental. Este estudio buscó fomentar nuevas discusiones sobre GSCM en Brasil.

PALABRAS CLAVE I Green Supply Chain Management, cadena de suministro verde, gestión ambiental en la cadena de suministros, sostenibilidad, escenario brasileño. 


\section{INTRODUÇÃO}

O modelo capitalista de produção vem desencadeando comportamentos sociais e hábitos de consumo caracterizados pelo desperdício de recursos naturais. Nesse sentido, a capacidade de produção mundial precisa ser mais eficiente na utilização desses recursos, de modo a reduzir seus impactos socioambientais e a garantir niveis de produção e consumo mais sustentáveis (Dalé, Roldan, \& Hansen, 2011; Vanchon \& Klassen, 2006), o que tem pressionado as organizações a incorporarem aspectos socioambientais em suas atividades. Desse modo, preocupações mais amplas com as pessoas e a natureza passaram a representar variáveis relevantes no processo operacional e na tomada de decisão (Kleindorfer, Singhal, \& Wassenhove, 2005). É notável o interesse em apurar possíveis convergências do tema sustentabilidade nas atividades gerenciais, suas influências e seus impactos nas estratégias intra e interorganizacionais (Brito \& Berardi, 2010).

A introdução efetiva de práticas em prol da sustentabilidade em empresas exige ações que extrapolam os limites organizacionais, abarcando o ambiente interorganizacional (Seuring \& Gold, 2013). Assim, empresas passam a ser analisadas de acordo com suas cadeias de suprimentos (Carvalho \& Barbieri, 2013). No que diz respeito à dimensão ambiental na cadeia de suprimentos, a adoção da Green Supply Chain Management (GSCM) pode ser considerada uma das alternativas para a redução dos impactos causados ao meio ambiente (Leal, Shibao, \& Moori, 2009; Rha, 2010). Além de agregar o aspecto ambiental, a GSCM oferece novo enfoque à responsabilidade das empresas com o meio ambiente, envolvendo um relacionamento compartilhado com fornecedores, órgãos governamentais, organizações não governamentais, consumidores e sociedade em geral (Andrade \& Paiva, 2012).

Crescentes pressões, a partir de distintos atores, têm levado gestores da cadeia de suprimentos a estudar e iniciar a introdução de práticas de GSCM para melhorar seu desempenho econômico e ambiental (Kumar \& Chandrakar, 2012). Nessa perspectiva, o conceito vem se desenvolvendo em diversos países, motivado pela necessidade do descarte ecologicamente correto de resíduos sólidos, do uso consciente dos recursos naturais e da redução da poluição da água e do ar, bem como pela influência da sociedade e pelas legislações pró-ambientais. No Brasil, a GSCM surge como tema pouco explorado nos estudos em Administração, aparecendo em pesquisas de logística reversa e de impactos ambientais (Minatti, Alberton, \& Marinho, 2011). As pesquisas a serem desenvolvidas no País ainda terão que traçar um caminho de construção conceitual. Essa nova área de estudo - envolvendo sustentabilidade e cadeia de suprimentos - comporta amplo espaço para o desenvolvimento de uma grande variedade de investigações (Leal et al., 2009).

Nesse contexto, questiona-se o papel da GSCM no País: coadjuvante ou protagonista no cenário nacional? Este artigo apresenta como objetivo analisar a difusão do conceito e das práticas de GSCM no contexto brasileiro. Para tanto, foram realizadas entrevistas com especialistas do tema Supply Chain Management na área de Administração no Brasil. 0 artigo está dividido em quatro partes, além desta introdução. Na primeira, realizou-se uma revisão acerca de compreensões da GSCM. Na segunda, descreve-se a metodologia utilizada neste estudo. Em seguida, apresenta-se a análise dos dados levantados. Por fim, mencionam-se as considerações finais, limitações do estudo e possibilidades de novas pesquisas.

\section{ENTENDENDO A GREEN SUPPLY CHAIN MANAGEMENT}

A cadeia de suprimentos, ou Supply Chain, é comumente definida como um caminho linear, que integra as atividades associadas ao fluxo e à transformação de bens, desde a extração de suas matérias-primas até o usuário final (Beamon, 1999; Seuring \& Müller, 2008). Inclui, ainda, atividades associadas ao fluxo de informação ao longo da cadeia. Algumas cadeias consideram também a etapa do pós-consumo, de modo que o resíduo gerado pelo bem tenha um destino final apropriado. Normalmente, a cadeia de suprimentos está sujeita a um gerenciamento que norteia suas operações. A gestão das operações dessa cadeia, ou Supply Chain Management (SCM), é conceituada como a coordenação estratégica e sistemática de processos-chave de negócios por uma empresa específica (a empresa focal), que visa ao contínuo aumento de vantagens competitivas e do desempenho dos elos e da própria cadeia (Mentzer et al., 2001).

Durante as últimas décadas, a gestão da cadeia de suprimentos passou a desempenhar um papel-chave no desempenho das empresas, como resultado de pressões de globalização, avanços na tecnologia da informação e aumento do nível de competitividade nos mercados (Rao \& Holt, 2005). As atividades desenvolvidas ao longo da cadeia de suprimentos ocasionam, todavia, sérios impactos ao ambiente, como o desperdício dos recursos naturais e as emissões de gases nocivos. A partir da crescente preocupação ambiental associada aos questionamentos sobre impactos de produção e consumo, cada vez mais atenções são direcionadas para o desenvolvimento de estratégias de gestão ambiental para as cadeias de suprimentos, o que acaba influenciando práticas e estratégias empresariais, 
critérios de desempenho organizacional, estágios do ciclo de vida dos produtos, processos logísticos etc. (Beamon, 1999; Brito \& Berardi, 2010; Sarkis, 2003).

Diante da crescente introdução de questões ambientais nos debates da economia mundial, emerge o conceito de Green Supply Chain Management (GSCM) - ou Gestão da Cadeia de Suprimentos Verde. A GSCM amplia o escopo da SCM, ao incluir aspectos ambientais aos critérios econômicos-financeiros de gerenciamento. Adicionar o componente "verde" à gestão da cadeia de suprimentos envolve abordar a influência e as relações entre o gerenciamento da cadeia e da natureza, visando equilibrar o desempenho empresarial com as preocupações ambientais (Kumar \& Chandrakar, 2012; Srivastava, 2007). Ainda, "esverdear" os diferentes elos da cadeia exige uma forte integração desta, podendo aumentar sua competitividade (Rao \& Holt, 2005).

A GSCM pode ser conceituada como a integração ambiental na cadeia de suprimentos, incluindo a concepção do produto, a procura e a seleção de material, os processos de fabricação, a entrega do produto final aos consumidores e a gestão do produto após o término do seu ciclo de vida (Srivastava, 2007). A GSCM refere-se ao modo pelo qual o contexto ambiental é considerado efetivamente nos processos de decisão da cadeia (Rha, 2010; Sarkis, 2003); assim, promove eficiência e sinergia entre os parceiros da cadeia e contribui para o aumento do desempenho ambiental, minimizando desperdícios e auxiliando a economia de custos (Rao \& Holt, 2005), sem sacrificar qualidade, custo, confiabilidade, desempenho ou eficiência no consumo de energia, a partir de três focos principais - ambiente, estratégia e logística (Andrade \& Paiva, 2012; Srivastava, 2007).

Entre os fatores que têm fortalecido o interesse por temas relacionados à gestão ambiental em cadeias de suprimento, destacam-se legislações mais rigorosas, casos de empresas expostas por conta de impactos ambientais em suas cadeias e a crescente integração de aspectos ambientais aos sistemas de gestão (Beamon, 1999; Seuring \& Müller, 2008). Assim, indica-se, como benefícios significativos da GSCM, redução de custos, maior facilidade de entrada no mercado global, redução da extração de recursos naturais, da mão de obra e do consumo de energia, substituição de materiais e matérias-primas, redução de resíduos, publicidade favorável, integração de fornecedores no processo de tomada de decisão, estratégias diferenciadas de compras, geração de vantagem competitiva, melhora no nível de satisfação do cliente, reforço da imagem da marca, desenvolvimento mais eficiente de novos produtos, melhora no relacionamento com agentes reguladores (Andrade \& Paiva, 2012; Rao \& Holt, 2005; Rountroy, 2009). Ademais, o uso de certificações ISO na cadeia de suprimentos parece favorecer a incorporação da filosofia verde (Rountroy, 2009).
Nessa perspectiva, a GSCM engloba atividades de redução de perdas, reciclagem, desenvolvimento de fornecedores, desempenho dos compradores, compartilhamento de recompensas e riscos, adoção de tecnologias mais limpas, adequações a normas e legislação, reutilização de materiais, economia no consumo de água e de energia, utilização de insumos ecologicamente corretos, processos de produção mais enxutos e flexíveis, responsabilidades para todos os participantes da cadeia (Bowen, Cousins, Lamming, \& Faruk, 2001). 0 uso do conjunto de ferramentas do GSCM conduz à melhoria do desempenho, a partir da capacitação de toda a cadeia de suprimento, por meio de acompanhamentos, medições, programas de melhoria e redução de custos em virtude do desenvolvimento de todos os envolvidos nela.

Diante disso, a gestão da cadeia de suprimentos verde visa promover ganhos econômicos e ambientais nos processos intrínsecos ao seu gerenciamento, contribuindo, ao mesmo tempo, com os interesses da sociedade e com os objetivos das organizações (Green, Morton, \& New, 1998; Srivastava, 2007). Para tanto, é preciso que exista comprometimento da organização para minimizar continuamente seus impactos ambientais e monitorar a otimização da alocação dos recursos produtivos (Minatti et al., 2011). Além disso, para que a excelência possa ser alcançada em toda a cadeia, a organização deve estabelecer uma relação de longo prazo de cooperação e parceria com seus fornecedores e compradores (Kumar \& Chandrakar, 2012; Vanchon \& Klassen, 2006).

\section{GSCM e Sustainable Supply Chain Management}

Na discussão da inserção da sustentabilidade na gestão da cadeia de suprimentos, Seuring e Müller (2008) argumentam que desenvolvimento sustentável é reduzido, normalmente, a meIhorias ambientais, desconsiderando aspectos referentes à dimensão social. Alguns estudos alegam que as questões sociais são pouco exploradas na gestão da cadeia de suprimentos (Ashby, Leat, \& Hudson-Smith, 2012; Brito \& Berardi, 2010; Carvalho \& Barbieri, 2013; Dalé et al., 2011; Pagell \& Wu, 2009; Seuring \& Müller, 2008; Wu, Dunn, \& Forman, 2012) e apontam a necessidade de um conceito mais amplo, envolvendo efetivamente as três dimensões da sustentabilidade - econômica, ambiental e social - para que um desempenho mais sustentável possa ser atingido (Pagell \& Wu, 2009). Surge, assim, o conceito de Sustainable Supply Chain Management (SSCM), ou gestão da cadeia de suprimentos sustentável.

A SSCM pode ser conceituada como a gestão dos fluxos de informação, material e capital, bem como a cooperação entre empresas ao longo da cadeia de suprimentos, com objetivos relacionados às dimensões econômica, ambiental e social 
do desenvolvimento sustentável. Entre os principais motivadores para a introdução da sustentabilidade na cadeia de suprimentos, estão a necessidade de adequação às pressões da sociedade, do governo e de entidades não governamentais, bem como o aumento da competitividade (Seuring \& Müller, 2008). Dessa forma, as práticas que conduzem a uma gestão da cadeia de suprimentos mais sustentável são melhores em comparação à gestão tradicional, exigindo uma nova postura quanto às questões ambientais e sociais (Pagell \& Wu, 2009).

Há necessidade muito maior de cooperação entre as empresas parceiras na gestão da cadeia de suprimentos sustentável (Seuring \& Müller, 2008). O engajamento de todos os membros da cadeia aparece como uma das maiores e mais importantes ferramentas à compreensão do significado de sustentabilidade, promovendo melhorias no desempenho das partes e do todo, criando vantagens competitivas e agregando valor nas operações e nas relações da cadeia. Nesse sentido, é preciso haver controles internos, monitoramento, integração, conscientização, engajamento e comunicação transparente, de modo a reduzir os danos ambientais e problemas sociais ao longo de toda a cadeia, contribuindo para que ela seja verdadeiramente sustentável (Brito \& Berardi, 2010; Pagell \& Wu, 2009; Wu et al., 2012).

\section{GSCM e SSCM em publicações}

Embora a GSCM esteja em evidência, sua implantação ainda é uma questão em aberto dentro das empresas (Bowen et al., 2001). Investimentos realizados para reduzir os impactos ambientais são bem vistos pela sociedade, assim os gestores precisam identificar as circunstâncias que levarão tais investimentos a favorecer não somente a geração de benefícios públicos mas também os lucros corporativos (Orsato, 2006). Srivastava (2007) realizou um estudo objetivando identificar obras importantes sobre a pesquisa da gestão da cadeia de suprimentos verde, baseado na análise de 227 artigos internacionais, publicados a partir de 1990. 0 autor identificou que assuntos estudados pelos pesquisadores da área são, em sua maioria, compartimentados e voltados para um assunto específico da GSCM ou para a área interna da empresa. Dessa maneira, inúmeros são os aspectos que podem influenciar a organização para a adoção de práticas verdes em suas operações, fazendo com que desperte sua consciência ambiental e coloque em ações ambientais em sua cadeia de suprimentos (Kumar \& Chandrakar, 2012).

Nessa circunstância, percebe-se que os estudos iniciais sobre o tema começam a ser desenvolvidos em países onde a questão ambiental já representa uma preocupação latente. $\mathrm{Na}$ pesquisa realizada por Wu et al.. (2012), foram evidenciadas as práticas de GSCM executadas pelas maiores corporações do mundo, listadas pela revista Fortune. Conforme o estudo, 38\% das matrizes das maiores empresas mundiais estão localizadas na Europa; $32 \%$ estão localizados na América do Norte e $27 \%$, na Ásia. Assim, é possível compreender o motivo pelo qual certas regiões, como a Europa, são líderes na inserção de práticas verdes na cadeia de suprimentos (Wu et al., 2012).

No Brasil, existem diversos estudos relacionados à logística reversa, mas poucos procuram analisar as práticas ambientais e sociais na cadeia de suprimentos. Souza e Ribeiro (2013) realizaram um estudo bibliométrico com intuito de investigar o perfil das pesquisas e a evolução do tema sustentabilidade ambiental em artigos publicados em periódicos nacionais Qualis de Administração de $A 1$ a B2, no período de 1992 a 2011. Dos 396 artigos identificados, apenas 10 englobavam cadeias de suprimento verdes. Todavia, ao longo da última década, é possível verificar certo crescimento da temática (ver, por exemplo, Andrade \& Paiva, 2012; Brito \& Berardi, 2010; Carvalho \& Barbieri, 2013; Dalé et al., 2011; Franco \& Jabbour, 2013; Leal et al., 2009; Lopes, Sacomano, Silva, \& Lopes, 2013; Minatti et al., 2011; Silva et al., 2013).

Nesse sentido, o tema permanece pouco explorado pelos estudos acadêmicos, e há escassos exemplos de aplicações de práticas em empresas brasileiras (Franco \& Jabbour, 2013). Por sua vez, o conceito de SSCM é mais recente e demanda maiores desenvolvimentos no campo teórico e empírico (Ashby et al., 2012). Considerada uma temática relativamente nova, a GSCM comporta amplo espaço para o desenvolvimento de grandes variedades de pesquisas. 0 desenvolvimento de estudos e suas publicações posteriormente no exterior podem contribuir para aumentar a representatividade do País em artigos sobre a temática da GSCM (Leal et al., 2009).

\section{MÉTODO}

Esta pesquisa busca compreender os motivos da pequena difusão do conceito e das práticas de GSCM, a partir da visão de pesquisadores em SCM sobre a GSCM no Brasil. Dessa forma, é classificada como qualitativa exploratória, visto que garante a riqueza dos dados, permite observar um fenômeno em sua totalidade e complexidade, além de facilitar a exploração de possíveis contradições e paradoxos (Vieira, 2006). Como técnica de coleta de dados, foi utilizada a entrevista com especialistas, com base em um roteiro semiestruturado. 0 roteiro inclui questionamentos acerca do lento desenvolvimento de conceitos e práticas de GSCM no Brasil, da percepção sobre o seu futuro no cenário nacional e da relação entre o conceito de GSCM e SSCM. As entrevistas foram registradas por meio de gravação em áudio e, posteriormente, transcritas. 
No estudo, foi empregado o método de amostragem não probabilística por julgamento, composta por especialistas do tema SCM da área Administração. Os estudiosos foram escolhidos em virtude de sua formação e experiência profissional - acadêmica ou técnica - e de suas contribuições relevantes para a área, bem como por indicação de outros especialistas. 0 contato inicial ocorreu por meio eletrônico, em que um e-mail foi encaminhado com uma breve explicação dos objetivos da pesquisa, juntamente com um convite para participação. No intuito de possibilitar maior conveniência aos participantes do estudo, as entrevistas configuraram-se de diferentes formas: três foram realizadas por meio telefônico, cinco deram-se por meio da utilização do programa Skype e uma das entrevistas foi realizada pessoalmente. Além disso, a participação de um respondente ocorreu a partir do envio do roteiro de entrevista por correio eletrônico, em virtude de sua agenda de compromissos.

Salienta-se que foram realizados 20 contatos. Em função da repetição das informações dadas pelos entrevistados, optou-se por encerrar a coleta de dados com uma amostra de nove entrevistas, mais as respostas enviadas por e-mail por um participante. Assim, entre os 10 respondentes, sete possuem o título de Doutor, atuando em programas de Pós-Graduação em áreas e linhas de pesquisas associadas à SCM. Por sua vez, os outros três estudiosos possuem o título de Mestre, com experiência de atuação profissional e acadêmica na área. As entrevistas ocorreram durante o mês de julho de 2012, com tempo médio de duração de 15 minutos. Com o intuito de preservar suas identidades, os entrevistados foram classificados por letras do alfabeto, conforme a ordem de realização das entrevistas.

Para o tratamento dos dados, utilizou-se a técnica da análise temática de conteúdo, proposta por Bardin (2009), a qual se baseia em realizar um desmembramento do texto em unidades, a partir dos diferentes núcleos de sentido, e, em seguida, o reagrupamento dessas unidades em classes ou categorias. Como método, a análise de conteúdo compreende um conjunto de técnicas de análise das comunicações que utiliza procedimentos sistemáticos e objetivos de descrição do conteúdo das mensagens. A autora aponta a necessidade de três etapas para a análise:

a. pré-análise do material coletado nas entrevistas: a pesquisa na literatura, a organização das notas de campo e dos dados secundários, e a transcrição das entrevistas. Ressalta-se que, nessa pesquisa, as categorias de análise foram identificadas a partir de grade aberta, por meio de procedimentos interpretativos dos relatos obtidos nas entrevistas (Bardin, 2009); b. análise e exploração do material propriamente dito: à medida que as entrevistas eram transcritas, o material era relido, com a marcação das passagens mais significativas, que gradualmente foram divididas em unidades de discurso nas categorias de análise, em sucessivas rodadas de agrupamento; e

c. tratamento dos resultados para constituição da análise reflexiva: a partir das categorias de análise, foram realizadas comparações com a literatura e inferências sobre os achados da pesquisa.

\section{ANÁLISE E INTERPRETAÇÃO DOS DADOS}

Dada a utilização da técnica de análise temática de conteúdo, foram identificadas categorias com base nos comentários dos especialistas considerados mais relevantes e mais frequentes para o contexto estudado. Ao analisar os motivos pelos quais os conceitos da GSCM não se desenvolveram no Brasil em comparação com outros países, quatro tópicos destacaram-se e foram elencados nas seguintes categorias: (a) características do mercado nacional; (b) foco empresarial em aspectos internos; (c) falta de legislação rígida; e (d) falta de pressão do mercado consumidor.

As questões de preocupação ambiental inseridas na cadeia de suprimentos representam um assunto relativamente novo. Conforme relatado nas entrevistas, o mercado brasileiro, comparado a outros países, apresenta atraso na implantação de práticas organizacionais. Nesse sentido, observa-se que as características do mercado nacional podem configurar-se como aspectos determinantes para o desenvolvimento da GSCM no Brasil. O entrevistado $\mathrm{G}$ argumenta que "tem uma diferença em termos do nível de maturidade do tema sustentabilidade nas empresas brasileiras quando comparadas com empresas principalmente europeias, onde esse assunto avançou”. Para o entrevistado A, “a Alemanha é um dos países que mais avançaram nesse tema, e nos países chamados em desenvolvimento ou economias emergentes usualmente as exigências vêm após esses primeiros movimentos". Seguindo a mesma perspectiva, o entrevistado $B$ afirma que:

Os próprios conceitos da Supply Chain Management se estabeleceram mais claramente na Europa e nos Estados Unidos, para então serem introduzidos no País. Na Europa, a Alemanha é um país que se destaca ao apresentar grandes preocupações com o meio ambiente. Na América do Norte, o Canadá figura como destaque em práticas verdes. Os Estados Unidos, por sua vez, por questões de redução de custos, passaram a ter maiores cuidados com a cadeia de suprimentos. 
Alguns entrevistados ressaltaram, entretanto, que é preciso ter cautela na comparação do Brasil com outros países. Para o pesquisador $\mathrm{H}$, "há uma visão distorcida sobre o assunto e fica parecendo que a Green Supply Chain Management não se desenvolveu no Brasil como em outros países. É preciso verificar quais são estes países, pois em relação a uns estamos melhores do que outros". Ainda, o entrevistado J alegou que a academia não acompanha o desenvolvimento de práticas realizadas pelas organizações, "nem todos os estudos conseguem refletir o que está acontecendo aqui”. Por sua vez, o especialista $\mathrm{C}$ acredita que, "tirando poucos países (Alemanha, por exemplo), a GSCM não é prática comum em lugar algum, e no Brasil não é diferente do outros”. Bowen et al., (2001) argumentam que organizações deverão adotar práticas verdes na gestão da cadeia de suprimentos a partir do momento em que identificarem que isso resultará em benefícios financeiros e operacionais - o que pode ser relacionado ao movimento de algumas empresas brasileiras que estão buscando integrar suas cadeias de suprimentos, bem como introduzir aspectos ambientais.

Nesse contexto, os entrevistados apontam que as empresas brasileiras estão mais intensamente focadas em aspectos internos. 0 entrevistado I afirma que "as empresas terceirizaram muito dos seus serviços [...] para diminuir custos internos e não para formar parcerias. Ainda tem muito dessa visão de pegar o melhor preço a melhor oferta do mercado, [...] salvando o seu lucro". 0 entrevistado $\mathrm{G}$ percebe que:

As empresas no Brasil vêm vivendo um ciclo onde mais intensamente o foco é fazer o que eu chamo de dever de casa, a melhoria dos processos, práticas, estratégias políticas e dentro do âmbito da organização, sem ainda ter condição ou capacidade de levar essas práticas para suas cadeias tanto do lado de fornecimento quanto do lado de distribuição e consumo [...] é esse estágio de olhar pra dentro inicialmente e depois para a cadeia.

Além disso, o pesquisador I argumenta que "as empresas ainda estão engatinhando no sistema em que o fornecedor seja um parceiro comercial Poucas empresas chegam a pensar nessa situação de cadeia produtiva”. Em uma pesquisa realizada com quatro empresas brasileiras, Dalé et al.. (2011) identificaram que empresas focais das cadeias pesquisadas desenvolviam diversas iniciativas sustentáveis, porém a incorporação dessas iniciativas na cadeia de suprimentos acontece lentamente. Por sua vez, o estudo de Andrade e Paiva (2012), que procurou analisar a cadeia de suprimentos de uma empresa do setor sucroal- cooleiro à luz dos conceitos de GSCM, constatou poucos processos de cooperação entre membros, o que seria importante para a sustentabilidade das operações no longo prazo.

Pode-se, assim, notar que as empresas nacionais encontram-se no estágio de desenvolvimento de estratégias de colaboração e cooperação entre os membros da cadeia de suprimentos (Machline, 2011). Conforme o estudo de Lopes et al., (2013), a colaboração entre membros da cadeia de suprimentos aparecem como a prática de GSCM que mais influencia o desempenho ambiental de empresas do setor automotivo brasileiro, corroborando a importância do relacionamento de parceria e de cooperação entre as empresas para reduzir o impacto ambiental da cadeia e aumentar sua performance. No mesmo sentido, o entrevistado F comenta que "ainda é difícil para nossa realidade [realidade brasileira] falar em Green Supply Chain, visto a dificuldade em encontrar uma cadeia integrada que atenda realmente a essa proposta”.

Em relação à legislação nacional, percebe-se que existe falta de pressão do governo, por meio de uma forte regulamentação, que incentive a inserção de práticas ambientais no contexto organizacional. $\mathrm{O}$ entrevistado $\mathrm{E}$ alega que, "de maneira geral, as empresas nacionais são reativas. 0 desempenho ambiental está atrelado ao cumprimento das leis, que devem reforçar a ideia de iniciativas verdes". Empresas proativas buscam melhores alternativas para reduzir seu impacto ambiental, considerando as questões ambientais questões de negócios (Orsato, 2006), enquanto empresas reativas buscam somente cumprir as legislações (Kumar \& Chandrakar, 2012). Os entrevistados argumentam que poucas empresas realizam ações ambientais voluntárias. Logo, a instituição de uma legislação mais rígida caracteriza-se como fator relevante ao desenvolvimento da GSCM no Brasil. Conforme Brito e Berardi (2010), a pressão legal e normativa leva empresas a adotarem práticas mais sustentáveis para a solução de problemas socioambientais.

De acordo com o entrevistado A, legislações que protegem o meio ambiente "primeiro acontecem nos países industrializados e depois vêm para os países mais periféricos". De fato, os avanços da GSCM nos países da União Europeia ocorreram significativamente em virtude da intensa regulamentação. Podem ser citadas como exemplos de políticas públicas vigorosas a Diretiva n. 442 do Conselho da Comunidade Europeia (1975), relacionada ao gerenciamento de resíduos sólidos; a Diretiva $\mathrm{n} .62$ (1994), referente à responsabilidade expandida dos produtores de embalagens e embaladores, com a finalidade de minimizar o volume de embalagens descartadas nos resíduos (Rao \& Holt, 2005); e a Diretiva n. 95 (2002), relacionada a restrições ao uso de certas substâncias perigosas em equipamentos eletroeletrônicos. 
Em seu estudo, Rha (2010) constatou que preocupações sociais e ambientais começaram a surgir no início da década de 1990 na Coreia do Sul, quando o governo estabeleceu novas leis para incentivar a prática da gestão ambiental. Em 2003, o governo coreano delineou normas para estratégias de GSCM para organizações. É consenso entre os entrevistados que o governo deve estabelecer regulamentações rigorosas juntamente com uma forte fiscalização, por parte dos órgãos responsáveis, para que as empresas passem a introduzir práticas ambientais em suas rotinas organizacionais. No mesmo sentido, o entrevistado $\mathrm{H}$ relata que, "sem uma política pública vigorosa, as coisas não acontecem. Não dá para esperar grandes avanços por meio de iniciativas voluntárias de empresas e seus clientes".

Nesse contexto, o entrevistado G alega que "empresas nacionais sofrem menos pressão dos agentes externos em relação às práticas na cadeia de suprimentos, o que é diferente de empresas europeias". No que tange às pressões do mercado consumidor, indicou-se que, em média, o consumidor brasileiro não cumpre um papel ativo na cobrança de práticas ambientais das empresas. Para o pesquisador D, "é cultura do consumidor brasileiro, que não exige isso [práticas ambientais] das empresas, e acaba tendo esse efeito dominó: esse consumidor não exige, então por que as pessoas que estão envolvidas na cadeia vão se preocupar com isso?". Os relatos indicam que consumidores ainda acreditam que as ações ambientais refletirão no aumento do preço do produto ou serviço, como argumenta o entrevistado A, e que, "ao final, a grande dificuldade das empresas é não conseguir um preço no mercado brasileiro que esteja dentro dos padrões esperados por ele para poder cobrir esses custos adicionais [custos ambientais]". Todavia, para Sarkis (2003), os benefícios das decisões relativas às questões ambientais não afetarão somente a organização que toma a decisão mas também seus fornecedores, distribuidores e, especialmente, seus clientes.

Com base nessas opiniões apresentadas pelos respondentes, foram evidenciadas perspectivas para o desenvolvimento da GSCM no Brasil. Segundo o entrevistado J, "parece que o processo de conscientização está acontecendo, o processo legal está em um bom caminho”. Por sua vez, o especialista $G$ alega que "as empresas que estão em uma posição de mais liderança no tema sustentabilidade acordaram para esse tema, e estão procurando [...] implementar processos e práticas". 0 entrevistado $\mathrm{F}$ ressalta, porém, que, "apesar de seu desenvolvimento, o processo de disseminação dos conceitos da GSCM não ocorrerá tão rapidamente quanto se deseja", ratificando a opinião do pesquisador B, que crê no desenvolvimento, mas "talvez não na velocidade que deveria, porque aí entra nossa cultura de baixa velocidade". 0 pesquisador D acredita que "isso [a implantação] é algo que vai demorar um pouquinho para alcançar o nível de outros países". Ainda, o entrevistado $\mathrm{H}$ pondera que "algumas cadeias irão responder mais rapidamente do que outras, principalmente em função dos setores que atuam".

Desse modo, ao serem analisadas as perspectivas para o desenvolvimento da GSCM no Brasil, foram apontadas três categorias: (a) Política Nacional dos Resíduos Sólidos; (b) pressão do mercado internacional; e (c) busca por certificação ambiental. A adoção de práticas ambientalmente corretas é motivada pelas pressões institucionais, pressões por padrões mínimos de competitividade e pressões da cadeia, já que tais variáveis fazem parte da realidade empresarial (Brito \& Berardi, 2010). Ainda, de acordo com Franco e Jabbour (2013), entre as motivações para a adoção de práticas de GSCM em empresas brasileiras do setor de baterias automotivas, estão o atendimento às normas e legislações governamentais e a pressão do mercado por práticas ambientalmente corretas.

No Brasil, a Política Nacional de Resíduos Sólidos foi instituída somente em 2010, com a Lei n. 12.305 (2010), reunindo o conjunto de princípios, objetivos, instrumentos, diretrizes, metas e ações adotado pelo governo em relação à gestão integrada e ao gerenciamento ambientalmente correto dos resíduos sólidos. Logo, as empresas devem mobilizar-se para atender às exigências da lei, elaborando seus planos de gestão de resíduos sólidos. Conforme o entrevistado A, "as empresas não querem correr o risco de não fazê-lo [o plano de gestão], porque o custo é mais alto [...]". Conforme Kumar e Chandrakar (2012), programas governamentais, que incentivam a adoção voluntária de ações ambientais, acabam incentivando indiretamente a adoção de práticas de GSCM. Muitas empresas estão começando a exigir que seus fornecedores atendam a requisitos relacionados ao meio ambiente, em função da responsabilidade compartilhada, determinada pela lei. Quando a empresa focal é pressionada, ela geralmente repassa essa pressão para os fornecedores (Seuring \& Müller, 2008). Assim, os relatos sugerem que a Política Nacional dos Resíduos Sólidos pode ser um incentivo para que conceitos da GSCM sejam disseminados entre as empresas.

Em relação à pressão do mercado externo, a maior exposição de empresas brasileiras a mercados globalizados obriga-as a adequar-se às legislações de outros países e a apresentar práticas ambientalmente desejadas e certificadas, como afirma o pesquisador $\mathrm{H}$ : “as empresas sofrem mais pressões quando estão atuando no mercado externo, e as questões ambientais envolvidas podem ser motivos para levantar barreiras ao comércio". Essa exposição, ainda, exige que as empresas estejam em busca de maior competitividade. 0 estudo de Rao e Holt (2005) em empresas asiáticas afirmou que as organizações que apli- 
cam práticas de GSCM são aquelas que possuem maior competitividade: melhoria da eficiência, da qualidade, da produtividade e redução de custos. Além disso, o entrevistado A relata que, "de alguma forma, as empresas multinacionais têm uma busca constante de disseminação de práticas entre diferentes unidades no mundo". Tal estratégia reflete-se na disseminação de conceitos como os da GSCM no Brasil. Logo, as questões institucionais de outros países podem afetar as cadeias das filiais localizadas no País e, num segundo momento, as cadeias das empresas nacionais.

As certificações ambientais e os sistemas de gestão ambiental cumprem um importante papel na resposta às pressões internacionais, visto que atribuem maior credibilidade às ações e práticas organizacionais. A ISO 14000, por exemplo, é uma norma gerencial que visa evidenciar impactos ambientais provenientes do processo de gerenciamento das atividades empresariais e do ciclo de vida dos produtos/serviços. Conforme o especialista A, "aqueles setores que são mais expostos à competição internacional ou estão mais inseridos no mercado global consequentemente têm mais pressões externas para se adequar a esses padrões ambientais". Para o entrevistado H, "as certificações ambientais cumprem importante papel nesse processo, não é por outra razão que empresas brasileiras que exportam [...] buscam esses certificados". A relação entre sistemas de gestão ambiental e as práticas da GSCM tem implicações significativas para a dimensão ambiental da sustentabilidade de uma organização, uma vez que as atividades desenvolvidas são potencialmente complementares (Minatti et al., 2011).

Os entrevistados acreditam que o processo para a obtenção de certificações de uma empresa pode contribuir para a certificação da cadeia como um todo. $O$ entrevistado E garante que “empresas que já têm um sistema de gestão ambiental implantado são aquelas que começam a cobrar práticas de gestão ambiental, desempenho ambiental de seus fornecedores". 0 pesquisador $\mathrm{H}$ alega que:

Para a obtenção das certificações, a empresa deve realizar ajustes em seus produtos e processos produtivos para atender à norma, o que muitas vezes torna-se necessário repassar para seus fornecedores e estes para os seus, de modo que os requisitos desejados acabam sendo implantados ao longo da cadeia de suprimentos a partir da estratégia interna de uma empresa.

Nessa perspectiva, o estudo de Rao e Holt (2005) em firmas asiáticas mostrou que algumas organizações estão trabalhando juntamente a fornecedores para reduzir as emissões, monitorar os fluxos de resíduos, configurar seus programas ambientais e, até mesmo, estender o apoio técnico para ajudá-los com a conservação dos recursos naturais. Ademais, Rha (2010) aponta que, para implantar práticas GSCM, empresas exigem melhorias na gestão ambiental de seus parceiros da cadeia de suprimento, ao fornecer programas de treinamento e compartiIhar seu sistema de gestão ambiental.

Salienta-se, entretanto, que a inserção da questão da sustentabilidade como um todo - com suas dimensões econômica, social e ambiental - além de permear todos os processos internos, passa também a ter relevância nos relacionamentos externos da empresa, englobando, assim, toda a cadeia de suprimentos (Leal et al., 2009). Segundo os entrevistados, as práticas atuais da GSCM ainda se concentram na redução de custos e prevenção da poluição. No entanto, mudanças positivas podem começar a ser percebidas, uma vez que as organizações passam a incorporar medidas sustentáveis em suas estratégias e práticas cotidianas (Wu et al., 2012). A partir de iniciativas voltadas à cadeia de suprimentos, os esforços direcionados para a inserção do tema sustentabilidade formarão uma base de práticas sustentáveis em todas as organizações envolvidas (Orsato, 2006).

Nessa perspectiva, de acordo com o entrevistado G, "eu percebo que o tema [GSCM] está amadurecendo no Brasil, e acho que, pela complexidade da nossa realidade, a gente não deve olhar para esse assunto apenas sob a perspectiva do Green, mas sob a perspectiva do Sustainable". 0 entrevistado $F$ alega que "a sustentabilidade pode ser comparada a um guarda-chuva, uma vez que existem inúmeras definições e interpretações de seus conceitos, 'o que dificulta o entendimento'”. Perspectivas sociais e questões ambientais passaram a ser introduzidas mais frequentemente no debate econômico, com o surgimento de diversas correntes, conceitos e definições, sendo notória uma falta de consenso entre eles (Brito \& Berardi, 2010). Assim, foi questionada a opinião dos entrevistados em relação a GSCM e a SSCM.

“A GSCM é a introdução de preocupações com os aspectos ambientais, ou seja, com tudo aquilo que interage ou pode interagir com o meio ambiente", como conceitua o entrevistado H. A GSCM surge em um contexto em que as questões referentes à degradação ao meio ambiente, bem como à exploração dos recursos naturais, começaram a ser abordadas de maneira mais crítica e evidente. Srivastava (2007) realizou um levantamento teórico sobre a literatura publicada sobre GSCM, de modo a facilitar o estudo, a prática e a pesquisa sobre o tema. Para o autor, GSCM pode ser conceituada como a integração ambiental na cadeia de suprimentos, o que inclui o design de produto, a procura e a seleção de material, os processos de fabricação, a entrega do produto final aos consumidores, bem como a gestão 
do produto após sua vida útil, envolvendo práticas de redução, reutilização, reciclagem, remanufatura, remontagem, logística reversa etc. Dessa forma, percebe-se que as ações verdes na cadeia de suprimentos englobam a combinação de duas dimensões da sustentabilidade, a econômica e a ambiental.

O entrevistado A afirma, no entanto, que "hoje talvez já não faça mais sentido pensar o Green sem estar integrado com as questões sociais e econômicas”. O pesquisador G complementa, ao abordar o surgimento dos conceitos:

Green surge nesse contexto mais europeu e americano onde a variável social não era tão evidente, tão prioritária, né? Então o conceito surge numa perspectiva de ecoeficiência, de redução do consumo de matéria-prima, de inovações com o foco mais ambiental. Enfim, a realidade é muito mais complexa do que essa, quando você amplia o olhar para os países em desenvolvimento.

A SSCM é considerada, assim, uma visão mais ampla em comparação à GSCM, uma vez que inclui questões sociais na cadeia. 0 entrevistado $C$ percebe a GSCM como uma das dimensões do SSCM, o que é corroborado pelo trabalho de Seuring e Müller (2008), que afirmam que a GSCM é parte de um conceito mais vasto, a SSCM. Brito e Berardi (2010) dizem que a SSCM conduziu a uma expansão das fronteiras e passa a contemplar mais processos que os anteriormente inseridos na GSCM. Nessa mesma lógica, o pesquisador $E$ afirma que "é incorreto usar a cadeia de suprimentos sustentável, se as questões econômica e social não estiverem atreladas, nos trabalhos acadêmicos e até mesmo nos trabalhos desenvolvidos pelas empresas focados em sustentabilidade".

Ademais, deve-se atentar para a tradução dos termos para a língua portuguesa, uma vez que o termo Gestão da Cadeia de Suprimentos Sustentável é empregado para abordar questões da GSCM e da SSCM. Todavia, a GSCM deve ser empregada quando abranger preocupações com o meio ambiente na cadeia de suprimentos, enquanto SSCM deve ser utilizada quando relacionar preocupações ambientais e sociais na cadeia. Logo, nota-se que a GSCM é uma parte da SSCM. É equivocado utilizar o termo gestão da cadeia sustentável se a variável social não estiver atrelada às dimensões econômicas e ambientais. O entrevistado E esclarece que "uma cadeia de suprimentos não pode ser definida como sustentável se não aborda aspectos sociais e econômicos, juntamente com a questão ambiental”.

Nesse contexto, diante do que foi discutido, construiuse um quadro síntese com as barreiras para implantar práticas de gestão ambiental na cadeia de suprimentos pela literatura, as quais estão apresentadas nos resultados, e as dificuldades acerca da implantação de práticas de GSCM indicadas pelos especialistas entrevistados nesta pesquisa.

\section{Quadro 1. Comparação entre barreiras apontadas na literatura e pelos especialistas}

\begin{tabular}{l|l}
\hline Barreiras da literatura & $\begin{array}{l}\text { Barreiras dos especialistas } \\
\text { entrevistados }\end{array}$ \\
\hline $\begin{array}{l}\text { Desenvolvimento de estratégias } \\
\text { para a cadeia de suprimentos } \\
\text { (Machline, 2011) }\end{array}$ & $\begin{array}{l}\text { Características do mercado } \\
\text { nacional brasileiro }\end{array}$ \\
\hline $\begin{array}{l}\text { Necessidade de cooperação } \\
\text { entre membros (Andrade \& } \\
\text { Paiva, 2012; Lopes et al., 2013) }\end{array}$ & $\begin{array}{l}\text { Foco empresarial em aspectos } \\
\text { internos }\end{array}$ \\
\hline $\begin{array}{l}\text { Falta de pressão legal e } \\
\text { normativa (Brito \& Berardi, } \\
\text { 2010; Rha, 2010) }\end{array}$ & Falta de legislação rígida \\
\hline $\begin{array}{l}\text { Falta de um papel ativo } \\
\text { por parte dos stakeholders } \\
\text { na cobrança de práticas } \\
\text { ambientais das empresas } \\
\text { (Sarkis, 2003) }\end{array}$ & $\begin{array}{l}\text { Falta de pressão do mercado } \\
\text { consumidor }\end{array}$ \\
\hline
\end{tabular}

\section{CONSIDERAÇÕES FINAIS}

Esta pesquisa objetivou analisar a difusão do conceito e das práticas de GSCM no Brasil. Dessa maneira, especialistas da área de SCM foram questionados acerca das razões para os conceitos da GSCM não terem se desenvolvido no Brasil em comparação com outros países. Verificou-se, assim, que as características do mercado nacional em virtude de atrasos na implantação de práticas organizacionais - quando se compara o mercado interno com mercados exteriores - foram uma das razões levantadas pelos entrevistados. Os especialistas apontaram, também, que a falta de pressão por parte do governo, por meio de rigorosa regulamentação e fiscalização, pode ser uma explicação para o lento desenvolvimento. Além disso, o foco empresarial para aspectos internos e, consequentemente, operações intraorganizacionais, e a falta de pressão exercida pelos consumidores, aparecem como possíveis explicações pelos respondentes.

A visão dos especialistas é, no entanto, positiva em relação ao desenvolvimento das práticas e conceitos da GSCM no Brasil. Nesse sentido, argumentaram que o tema vem crescendo no País, bem como as perspectivas para o futuro, a partir da consolidação da Política Nacional dos Resíduos Sólidos, do au- 
mento das pressões do mercado internacional - que, cada vez mais, exige boas práticas ambientais - e da busca por certificação ambiental, que se reflete nos membros da cadeia de suprimentos. Ainda, os respondentes relataram suas opiniões sobre as diferenças entre os conceitos da GSCM e da SSCM, na qual a dimensão social não pode ser desconsiderada.

Pode-se compreender, portanto, que os pesquisadores entrevistados consideram que a GSCM está se desenvolvendo, deixando de ser um conceito coadjuvante para tornar-se protagonista no cenário brasileiro. Ademais, complementam que a realidade complexa brasileira apresenta a questão social como variável crítica, sugerindo que o papel protagonista deveria caber à SSCM. Assume-se que o cenário nacional deve realizar maiores pressões por meio de legislações rigorosas para que tal papel possa ser cumprido. Ainda, o mercado consumidor precisa compreender a sua influência no desenvolvimento de estratégias organizacionais, fazendo com que práticas mais responsáveis sejam introduzidas nas rotinas das empresas e de suas cadeias de suprimentos. Portanto, compreende-se que, mais do que adicionar a variável ambiental na cadeia de suprimentos, a GSCM pode proporcionar às empresas brasileiras uma alternativa para se repensar o modo de produção atual e contribuir com um desenvolvimento mais sustentável.

Como limitação do estudo, apresentam-se o tamanho da amostra e sua classificação não probabilística por julgamento. Os dados coletados refletem as opiniões e comentários dos estudiosos acerca do tema, dessa maneira, outros participantes poderiam atribuir diferentes respostas aos questionamentos realizados. De tal modo, indicam-se, como pesquisas futuras: analisar opiniões de maior número de especialistas; entrevistar especialistas de outras áreas; entrevistar gestores públicos e privados com conhecimento na temática para dar maior densidade ao estudo; analisar o nível de publicação em revistas ou eventos nacionais para verificar se há efetivamente um aumento de pesquisas sobre GSCM e SSCM; e realizar pesquisas empíricas sobre a temática em empresas brasileiras. Ainda, a realização de um estudo sobre o estado da arte da GSCM pode trazer grandes contribuições às discussões do tema no Brasil.

\section{REFERÊNCIAS}

Andrade, M. C. F, \& Paiva, E. L. (2012). Green supply chain management na agroindústria canavieira: o caso Jalles Machado. BASE - Revista de Administração e Contabilidade da Unisinos, 9(1), 2-12.

Ashby, A, Leat, M, \& Hudson-Smith, M. (2012). Making connections: a review of supply chain management and sustainability literature. Supply Chain Management: an International Journal, 17(5), 497-516.
Bardin, L. (2009). Análise de conteúdo (4a ed.). Lisboa: Edições 70.

Beamon, B. M. (1999). Designing the green supply chain. Logistics Information Management, 12(4), 332-342.

Bowen, F. E, Cousins, P. D, Lamming, R. C, \& Faruk, A. C. (2001, Autumn). Horses for courses: explaining the gap between the theory and practice of green supply. Greener Management International, 151-172.

Brito, R. P, \& Berardi, P. C. (2010). Vantagem competitiva na gestão sustentável da cadeia de suprimentos: um metaestudo. RAE-Revista de Administração de Empresas, 50(2), 155-169.

Carvalho, A. P, \& Barbieri, J. C. (2013). Inovações socioambientais em cadeias de suprimento: um estudo de caso sobre o papel da empresa focal. RAl - Revista de Administração e Inovação, 10(1), 232-256.

Dalé, L. B. C, Roldan, L. B, \& Hansen, P. B. (2011). Analysis of sustainability incorporation by industrial supply chain in Rio Grande do Sul state (Brazil). JOSCM - Journal of Operations and Supply Chain Management, 4(1), 25-36.

Franco, D, \& Jabbour, A. B. L. S. (2013). Identificação das motivações e barreiras para a adoção de práticas ambientais em cadeias de suprimentos: estudo de casos no setor de baterias automotivas. Anais do Simpósio de Administração da Produção, Logística e Operações Internacionais, São Paulo, 16.

Green, K, Morton, B, \& New, S. (1998). Green purchasing and supply policies: do they improve company's environmental performance? Supply Chain Management: an International Journal, 3(2), 89-95.

Kleindorfer, P. R, Singhal, K, \& Wassenhove, L. N. van. (2005). Sustainable operations management. Production and Operations Management, 14(4), 482-492.

Kumar, R, \& Chandrakar, R. (2012). Overview of green supply chain management: operation and environmental impact at different stages of the supply chain. International Journal of Engineering and Advanced Technology, 1(3), 1-6.

Leal, C. C, Shibao, F. Y, \& Moori, R. G. (2009). Principais autores sobre green supply chain no âmbito internacional. Anais dos Seminários em Administração, São Paulo, 12.

Lei n. 12.305. (2010). Política Nacional de Resíduos Sólidos. Recuperado em 10 dezembro, 2012, de http://www.planalto.gov.br/ccivil_03/_ ato2007-2010/2010/lei/l12305.htm.

Lopes, L. J, Sacomano, M, Neto, Silva, E. M, \& Lopes, F. C. C. (2013). Influência das práticas do green supply chain management no desempenho ambiental das empresas do setor automotivo brasileiro. Anais do Encontro Nacional da Associação Nacional dos Programas de Pós-Graduação em Administração, Rio de Janeiro, 37.

Machline, C. (2011). Cinco décadas de logística empresarial e administração da cadeia de suprimentos no Brasil. RAE-Revista de Administração de Empresas, 51(3), 227-231.

Mentzer, J, Dewitt, W, Keebler, J. S, Min, S, Nix, N. W, Smith, C. D, \& Zacharia, Z. G. (2001). Defining supply chain management. Journal of Business Logistics, 22(2), 1-25.

Minatti, C, Alberton, A, \& Marinho, S. V. (2011). Direções e construtos do green supply chain management. Anais do Simpósio de Administração da Produção, Logística e Operações Internacionais, São Paulo, 14.

Orsato, R. J. (2006). Competitive environmental strategies: when does it pay to be green? California Management Review, 48(2), 127-143.

Pagell, M, \& Wu, Z. (2009). Building a more complete theory of sustainable supply chain management using case studies of 10 exemplars. Journal of Supply Chain Management, 45(2), 37-56. 
Rao, P, \& Holt, D. (2005). Do green supply chains lead to competitiveness and economic performance? International Journal of Operations \& Production Management, 25(9), 898-916.

Rha, J. S. (2010, July). The impact of green supply chain practices on supply chain performance. Theses, College of Business Administration, University of Nebraska, Lincoln.

Rountroy, S. (2009). Antecedents and drivers for green supply chain management implementation in manufacturing environment. Birla Institute of Technology \& Science, Pilani, The Icfai University.

Sarkis, J. (2003). A strategic decision framework for green supply chain management. Journal of Cleaner Production, 11(4), 397-409.

Seuring, S, \& Gold, S. (2013). Sustainability management beyond corporate boundaries: from stakeholders to performance. Journal of Cleaner Production, 56(1), 1-6.

Seuring, S, \& Müller, M. (2008). From a literature review to a conceptual framework for sustainable supply chain management. Journal of Cleaner Production, 16(15), 1699-1710.
Silva, M. E, Neutzling, D. M, Alves, A. P. F, Dias, P, Santos, C. A. F, \& Nascimento, L. F. M. (2013). Gestão da cadeia de suprimentos sustentável: entendendo o discurso brasileiro. Anais do Encontro Nacional da Associação Nacional dos Programas de Pós-Graduação em Administração, Rio de Janeiro, 37.

Souza, M. T. S, \& Ribeiro, H. C. M. (2013). Sustentabilidade ambiental: uma meta-análise da produção brasileira em periódicos de administração. RAC-Revista de Administração Contemporânea, 17(3), 368-396.

Srivastava, S. K. (2007). Green supply-chain management: a state-of the-art literature review. International Journal of Management Reviews, 9(1), 53-80.

Vanchon, S, \& Klassen, R. D. (2006). Green project partnership in the supply chain: the case of the package printing industry. Journal of Cleaner Production, 14(6-7), 661-671.

Vieira, M. M. F. (2006). Por uma boa pesquisa (qualitativa) em administração. In M. M. F. Vieira, \& D. M. Zouain. Pesquisa qualitativa em administração (2a ed.). Rio de Janeiro: FGV.

Wu, J, Dunn, S, \& Forman, H. (2012). A study on green supply chain management practices among large global corporations. Journal of Supply Chain and Operations Management, 10(1), 182-194. 